\title{
PENERAPAN METODE WATERFALL PADA APLIKASI LAUNDRY BERBASIS WEB
}

\author{
Fauzi Yusa Rahman \\ ${ }^{1)}$ Fakultas Teknologi Informasi, Universitas Islam Kalimantan MAB Banjarmasin \\ email: fauziyusarahman@gmail.com
}

\begin{abstract}
Abstrak
Dinda Laundry merupakan salah satu jasa pelayanan laundry yang beralamat di perumahan Batola Residence, Handil Bakti. Dinda Laundry melayani dalam jasa cuci setrika, cuci kering, dan setrika saja. Pada saat ini pengelolaan data pelayanan laundry masih bersifat manual, yaitu pelanggan datang untuk pelayanan cuci, kemudian data pelanggan dicatat pada nota, nota tersebut terdiri dari dua lembar yaitu lembar warna putih dan lembar warna merah. Nota dengan lembar merah di bawa oleh pelanggan. Apabila pelayanan laundry sudah selesai dilakukan maka pelanggan harus menunjukkan nota merah untuk mengambil pakaian yang sudah selesai di cuci. Pengelolaan data masih menggunakan buku yang ditulis secara manual. Hal ini tentu saja banyak memiliki banyak kekurangan yang mungkin mengganggu dalam pengelolaan data, bisa saja terjadi kesalahan penulisan dan kesulitan dalam mencari data transaksi. Oleh karena itu peneliti akan membuat sebuah aplikasi berbasis web yang akan menyimpan semua data pelanggan yang melakukan pelayanan laundry dan data pelayanan yang dilakukan. Aplikasi pelayanan laundry menggunakan metode waterfall, pada metode ini menggambarkan pendekatan yang sistematis dan juga berurutan pada pengembangan perangkat lunak, dimulai dengan spesifikasi kebutuhan pengguna lalu berlanjut melalui tahapan perencanaan (planning), permodelan (modeling), konstruksi (construction), serta penyerahan sistem ke pengguna (deployment), yang diakhiri dengan dukungan pada perangkat lunak lengkap yang dihasilkan.
\end{abstract}

Kata kunci: waterfall, web, dinda laundry

\section{PENDAhuluan}

Dinda Laundry merupakan salah satu jasa pelayanan laundry yang beralamat di perumahan Batola Residence, Handil Bakti. Dinda Laundry melayani dalam jasa cuci setrika, cuci kering, dan setrika saja yang terdiri atas dua jenis paket yaitu standart 2 hari dan expres 1 hari. Harga yang ditetapkan pada pelayanan dinda laundry tergatung dari jenis paket yang diinginkan dan berat pakaian.

Berdasarkan wawancara yang dilakukan degan pemilik Dinda Laudry, pada saat ini pengelolaan data pelayanan laundry masih bersifat manual, yaitu pelanggan datang untuk pelayanan cuci, kemudian data pelanggan dicatat pada nota, nota tersebut terdiri dari dua lembar yaitu lembar warna putih dan lembar warna merah. Nota dengan lembar merah di bawa oleh pelanggan, sedangkan lembar putih disimpan. Apabila pelayanan laundry sudah selesai dilakukan maka pelanggan harus menunjukkan nota merah untuk mengambil pakaian yang sudah selesai di cuci. Pengelolaan data masih menggunakan buku yang ditulis secara manual. Hal ini tentu saja banyak memiliki banyak kekurangan yang mungkin mengganggu dalam pengelolaan data, bisa saja terjadi kesalahan penulisan dan kesulitan dalam mencari data transaksi.

Hal ini tentu saja memiliki berbagai macam kekurangan, yaitu data pelayanan yang berupa nota tentu saja mungkin hilang atau rusak, bahkan kesulitan bagi pegawai yaitu bagaimana mengingat data pelanggan dan jenis pelayanan landry yang digunakan, karna tidak adanya media penyimpanan yang baik. Oleh karena itu peneliti akan membuat sebuah aplikasi laundry berbasis web yang akan menyimpan semua data pelanggan, dan pelayanan yang digunkan.

\section{METODE PENELITIAN}

Penerapan aplikasi pelayanan pada Dinda Laundry menggunakan metode waterfall sering disebut dengan siklus hidup klasik (classic life cycle), metode ini menggambarkan pendekatan yang sistematis dan berurutan pada pengembangan perangkat lunak. 
Metode waterfall memiliki beberapa tahapan yang berurut yaitu: requirement analysis (analisis kebutuhan), design system (desain sistem), coding (pengkodean) dan testing (pengujian), dan maintenance (pemeliharaan).

Dalam pengembangan perangkat lunak terdapat beberapa tahapan-tahapan yang harus dilakukan, adapun tahapan tersebut adalah sebagai berikut:

a. Requirement Analysis

Tahapan analisa kebutuhan ini diperlukan komunikasi yang bertujuan untuk memahami perangkat lunak yang diharapkan oleh pengguna dan batasan perangkat lunak tersebut. Informasi ini biasanya dapat diperoleh melalui wawancara, diskusi atau survei langsung.

b. Design System

Tahapan desain sistem merupakan spesifikasi kebutuhan dari sistem. Desain sistem membantu dalam menentukan perangkat keras (hardware) dan sistem persyaratan dan juga membantu dalam mendefinisikan arsitektur sistem secara keseluruhan.

c. Coding

Tahapan koding merupakan pertama kali dikembangkan program kecil yang disebut unit, yang terintegrasi dalam tahap selanjutnya.

d. Testing

Tahapan testing seluruh unit yang dikembangkan dalam tahap implementasi diintegrasikan ke dalam sistem setelah pengujian yang dilakukan masing-masing unit. Setelah integrasi seluruh sistem diuji untuk mengecek setiap kegagalan maupun kesalahan.

e. Maintenance

Tahapan maintenance merupakan tahap akhir dalam metode waterfall. Perangkat lunak yang sudah jadi, dijalankan serta dilakukan pemeliharaan. Pemeliharaan termasuk dalam memperbaiki kesalahan yang tidak ditemukan pada langkah sebelumnya. Perbaikan implementasi unit sistem dan peningkatan jasa sistem sebagai kebutuhan baru.

\subsection{Analisa Sistem}

Dalam membuat dan mengembangkan suatu aplikasi sangat diperlukan suatu perencanaan agar dihasilkan sebuah aplikasi yang dapat berjalan efektif, efisien dan sesuai dengan keinginan. Tahap perencanaan ini terbagi atas:

a. Menentukan tujuan pembuatan aplikasi

Tujuan penelitian ini adalah agar memberikan kemudahan baik bagi pemilik, karyawan maupun pelanggan untuk melakukan proses serah terima hasil pelayanan, maupun proses pencarian data pelanggan secara cepat dan mudah.

b. Menentukan siapa yang akan menjadi pemakai.

Aplikasi data pelayanan pasa Dinda Laundry ini digunakan oleh administrator, kemudian dilanjutakan oleh karyawan yang melakukan pelayanan dan terakhir pemilik untuk melihat data laporan.

\subsection{Perancangan Sistem}

Proses perancangan diperlukan dalam pembuatan aplikasi yang baik. Perancangan sistem secara terperinci, dilakukan dengan cara:

a. Perancangan Menu

b. Perancangan Basis Data

c. Perancangan Relasi Tabel

d. Perancangan Diagram Konteks

e. Hasil Tampilan

f. Hasil Laporan

\subsection{Testing Aplikasi}

Pada tahapan testing aplikasi ini, dilakukan uji terhadap sistem yang telah selesai dibuat dengan menggunakan satu buah laptop. setiap proses pendataan dilakukan langsung pada servel lokal (localhost) agar aplikasi berjalan sesaui keinginan.

\section{HASIL DAN PEMBAHASAN}

Aplikasi pelayanan Dinda Laundry terdiri dari tiga level pengguna, yaitu administrator, karyawan, dan pemilik. Aplikasi pelayanan Dinda Laundry bisa di pakai secara offline maupun online.

\subsection{Perancangan Menu}

Perancangan menu pada aplikasi data pelayanan Dinda Laundry terdiri atas 3 level pengguna. Berikut Perancangan menu yang terbentuk: 
1. Menu Level Administrator
a. Login
b. Beranda
c. Modul
d. Pengguna
e. Jenis Pelayanan
f. Pelayanan Proses
g. Pelayanan Selesai
h. Pelayanan Diambil
i. Pelayanan Batal
j. Laporan
k. Tentang
1. Keluar

2. Menu Level Karyawan
a. Login
b. Beranda
c. Pelayanan Proses
d. Pelayanan Selesai
e. Pelayanan Diambil
f. Pelayanan Batal
g. Laporan
h. Tentang
i. Keluar

3. Menu Level Pemilik
a. Login
b. Beranda
c. Laporan
d. Tentang
e. Keluar

\subsection{Perancangan Basis Data}

Perancangan basis data digunakan untuk mengidentifikasi kebutuhan tabel yang diperlukan. Perancangan basis data pada aplikasi pelayanan laundry menggunakan database MySQL pada aplikasi PHPMyAdmin dan diberi nama db-dlaundry, berikut tabeltabel yang terbentuk:

1. Tabel Modul

2. Tabel Pengguna

3. Tabel Jenis

4. Tabel Pelayanan

\subsection{Perancangan Relasi Tabel}

Relasi tabel digunakan untuk melihat tabel-tabel mana saja yang terhubung. Berikut relasi antar tabel yang terbentuk:

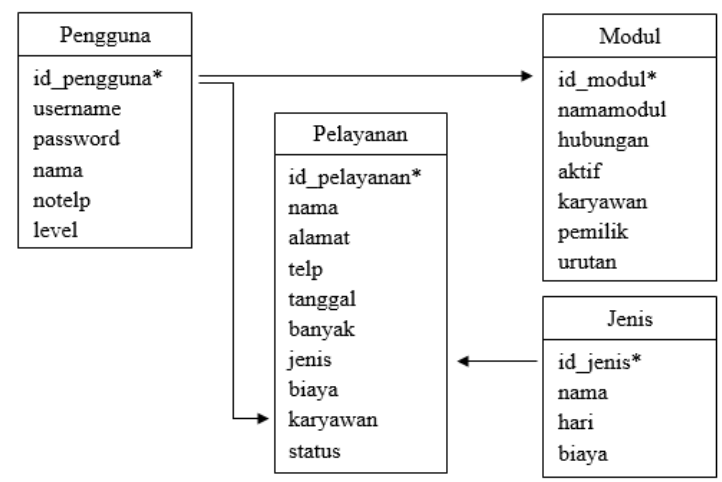

Gambar 1. Relasi Tabel

\subsection{Perancangan Diagram Konteks}

Diagram konteks digunakan untuk melihat proses dari aplikasi, dari mana dan kemana proses dilakukan. Berikut Perancangan diagram konteks yang terbentuk dalam aplikasi pelayanan Dinda Laundry:

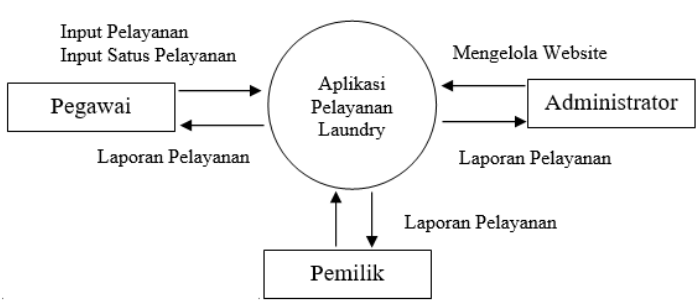

Gambar 2. Diagram Konteks

\subsection{Hasil Tampilan}

Hasil tampilan merupakan hasil dari aplikasi pelayanan laundry yang sudah diselesaikan, berikut tampilan aplikasi berdasarkan level pengguna:

\section{Tampilan Level Administrator}

a. Tampilan Halaman Login

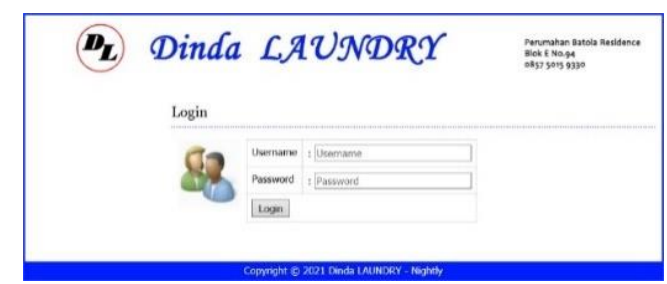

Gambar 3. Tampilan Halaman Login Level Administrator 
b. Tampilan Halaman Beranda

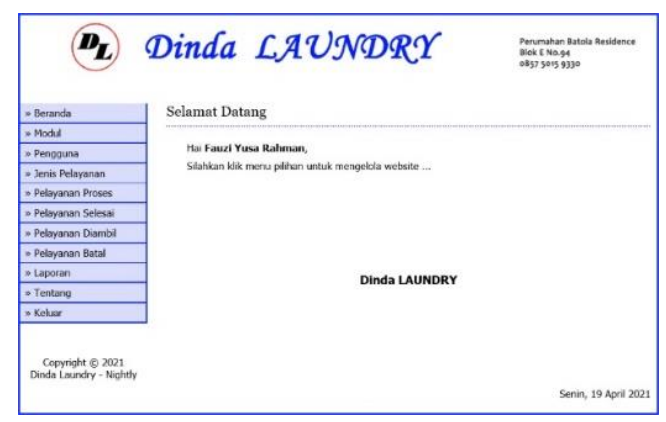

Gambar 4. Tampilan Halaman Beranda Level Administrator

c. Tampilan Halaman Modul

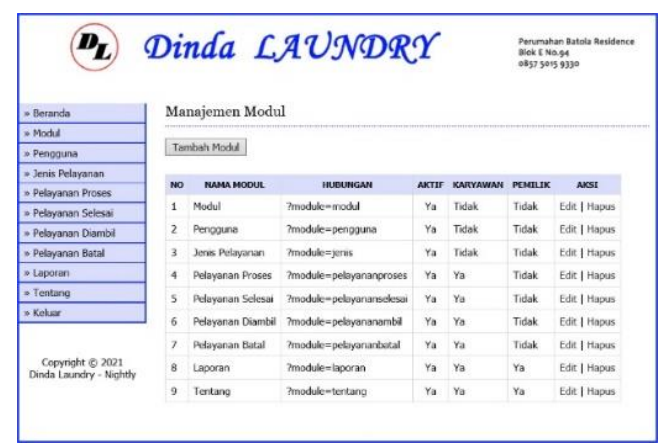

Gambar 5. Tampilan Halaman Modul Level Administrator

d. Tampilan Halaman Pengguna

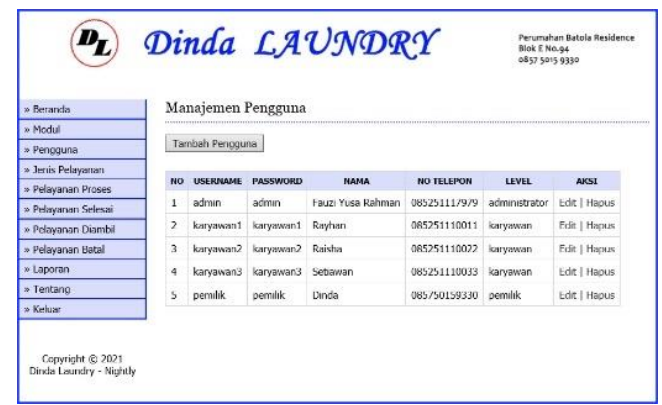

Gambar 6. Tampilan Halaman Pengguna Level Administrator

e. Tampilan Halaman Jenis Pelayanan

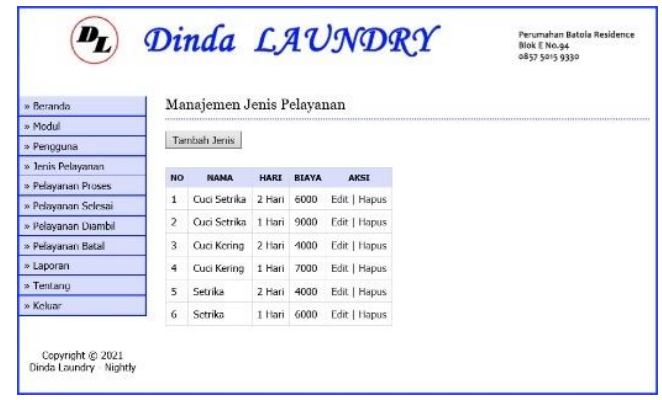

Gambar 7. Tampilan Halaman Jenis Pelayanan Level Administrator f. Tampilan Halaman Pelayanan Proses

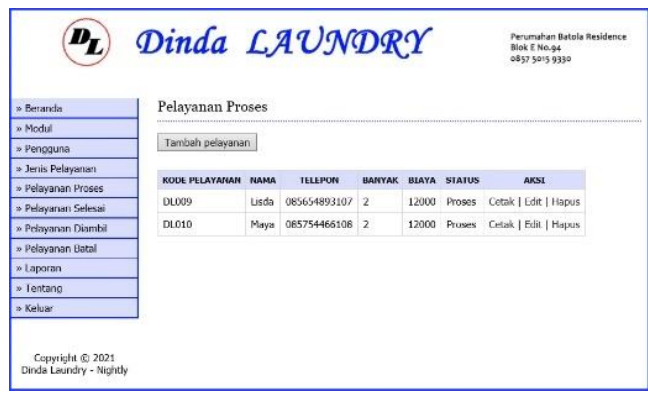

Gambar 8. Tampilan Halaman Pelayanan Proses Level Administrator

g. Tampilan Halaman Pelayanan Selesai

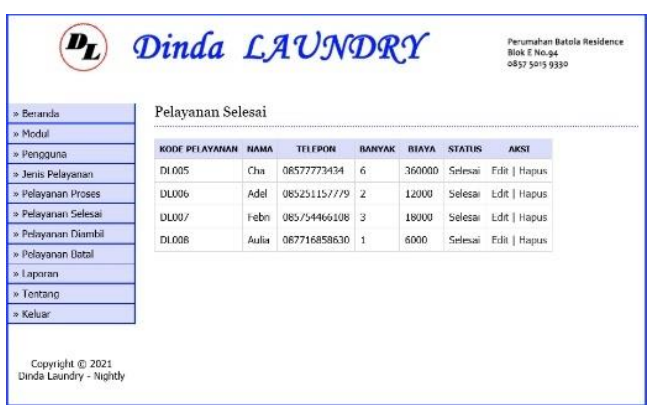

Gambar 9. Tampilan Halaman Pelayanan Selesai Level Administrator

h. Tampilan Halaman Pelayanan Diambil

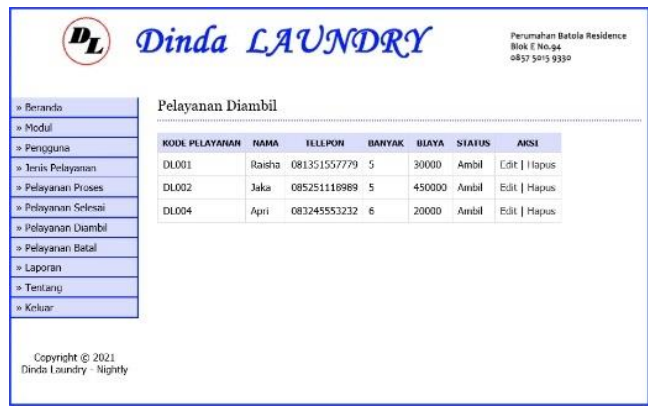

Gambar 10. Tampilan Halaman Pelayanan Diambil Level Administrator

i. Tampilan Halaman Pelayanan Batal

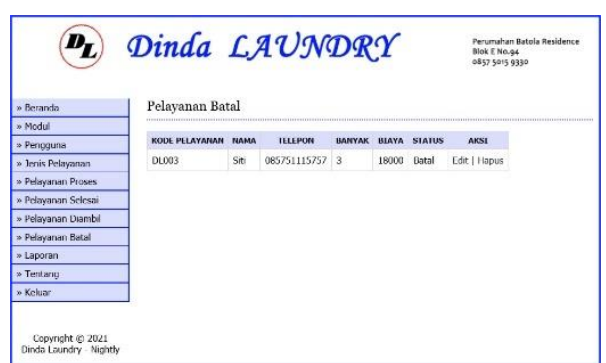

Gambar 11. Tampilan Halaman Pelayanan Batal Level Administrator 
j. Tampilan Halaman Laporan

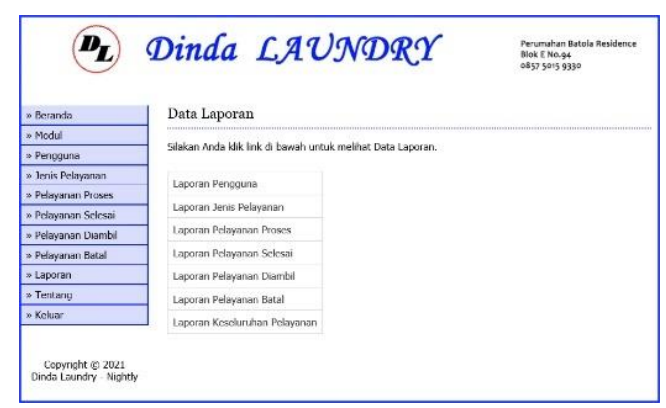

Gambar 12. Tampilan Halaman Laporan Level Administrator

k. Tampilan Halaman Tentang

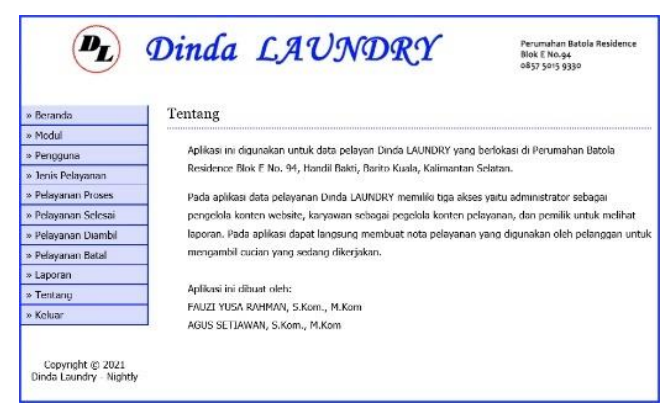

Gambar 13. Tampilan Halaman Tentang Level Administrator

\section{Tampilan Halaman Level Karyawan}

a. Tampilan Halaman Login

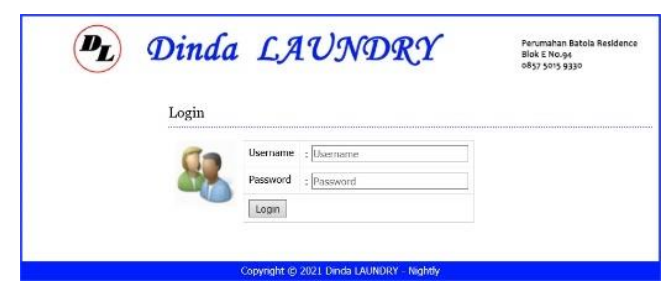

Gambar 14. Tampilan Halaman Login Level Karyawan

b. Tampilan Halaman Beranda

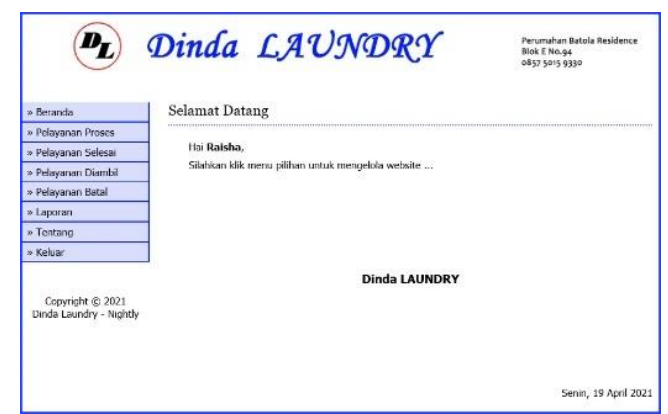

Gambar 15. Tampilan Halaman Beranda Level Karyawan c. Tampilan Halaman Pelayanan Proses

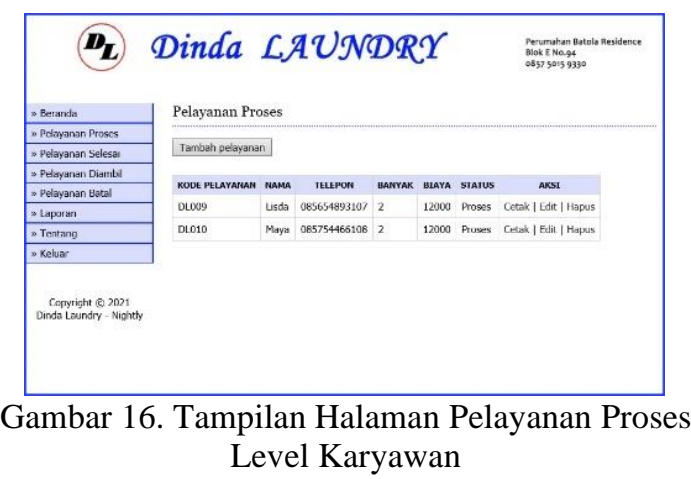

d. Tampilan Halaman Pelayanan Selesai

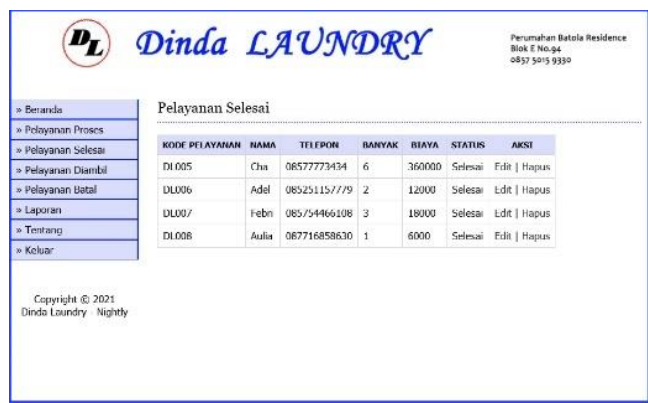

Gambar 17. Tampilan Halaman Pelayanan Selesai Level Karyawan

e. Tampilan Halaman Pelayanan Diambil

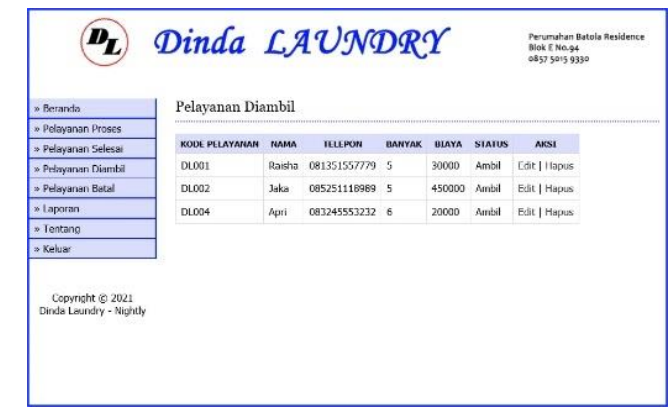

Gambar 18. Tampilan Halaman Pelayanan Diambil Level Karyawan

f. Tampilan Halaman Pelayanan Batal

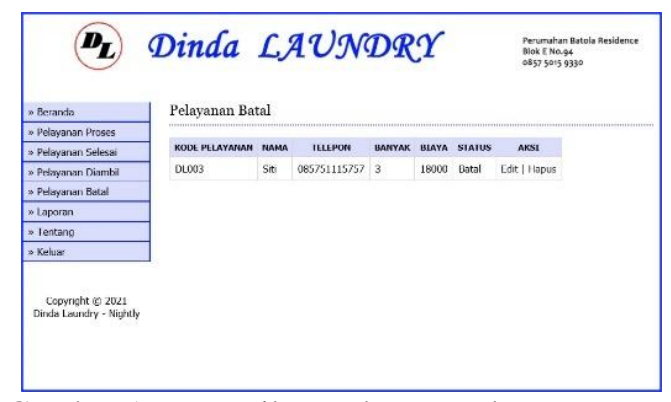

Gambar 19. Tampilan Halaman Pelayanan Batal Level Karyawan 
g. Tampilan Halaman Laporan

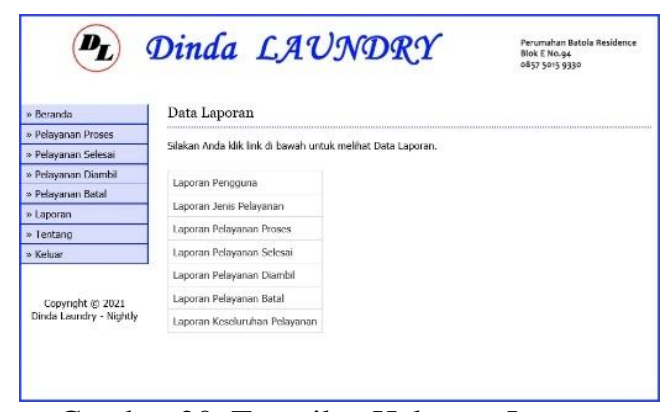

Gambar 20. Tampilan Halaman Laporan Level Karyawan

h. Tampilan Halaman Tentang

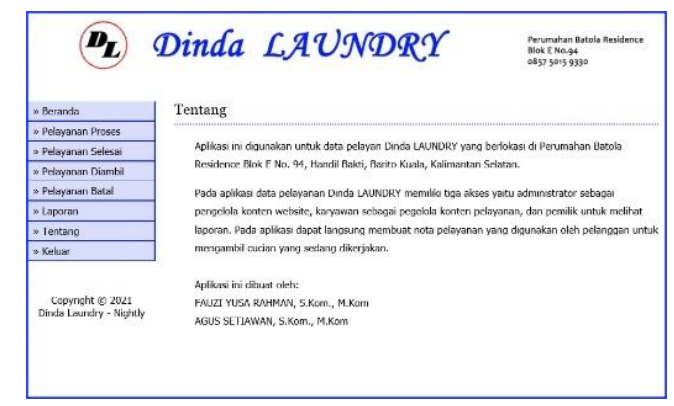

Gambar 21. Tampilan Halaman Tentang Level Karyawan

\section{Tampilan Halaman Level Pemilik}

a. Tampilan Halaman Login

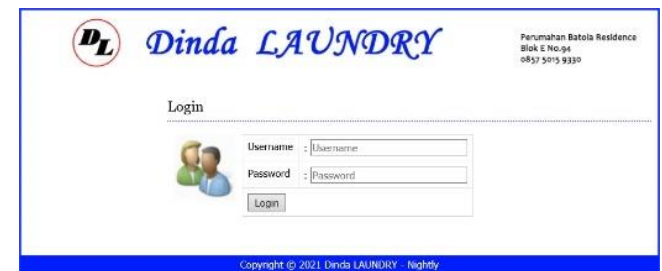

Gambar 22. Tampilan Halaman Login Level Pemilik

b. Tampilan Halaman Beranda

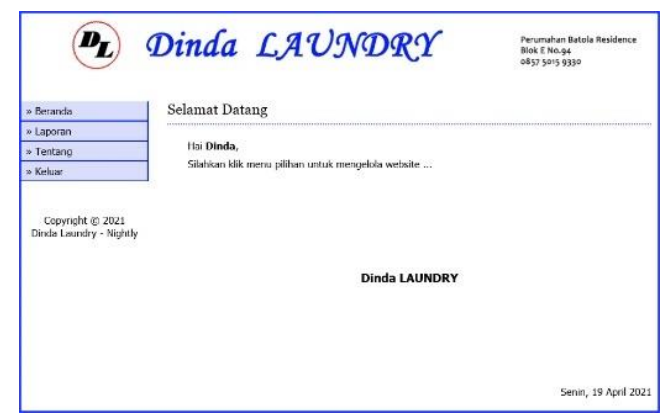

Gambar 23. Tampilan Halaman Beranda Level Pemilik c. Tampilan Halaman Laporan

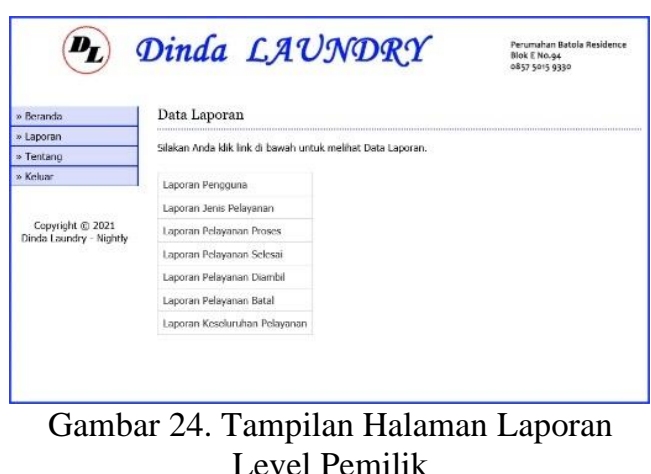

d. Tampilan Halaman Tentang

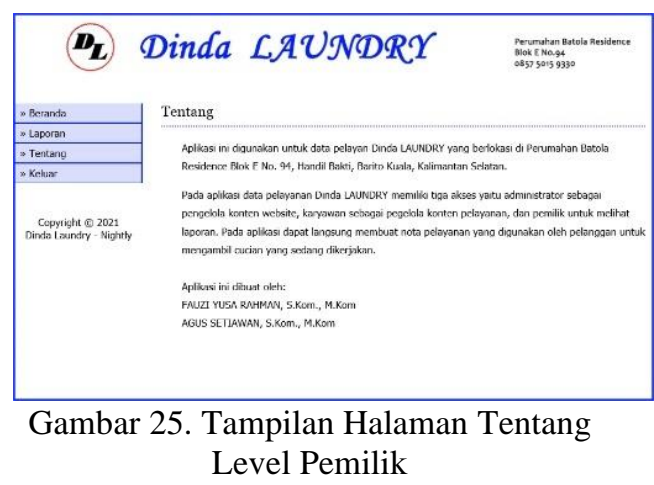

\subsection{Hasil Laporan}

Hasil tampilan merupakan hasil dari aplikasi pelayanan laundry yang sudah diselesaikan, berikut tampilan laporan yang dibuat:

1. Laporan Nota Data Pelayanan

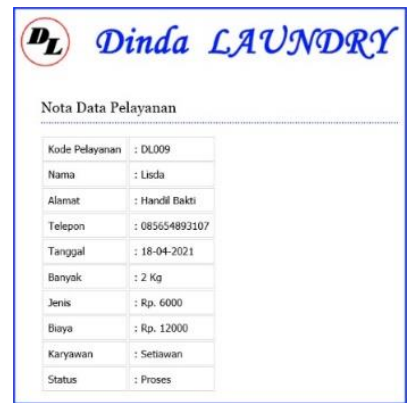

Gambar 26. Laporan Nota Data Pelayanan

2. Laporan Jenis Pelayanan

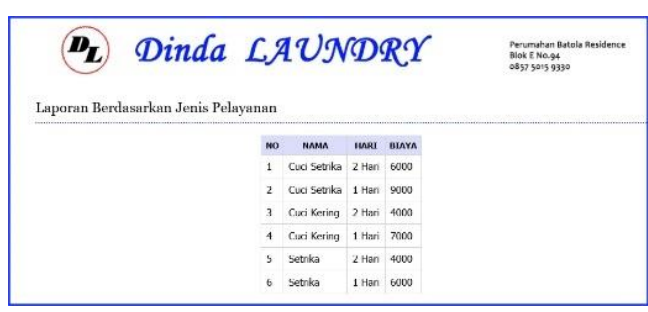

Gambar 27. Laporan Jenis Pelayanan 
3. Laporan Berdasarkan Pelayanan Masih Proses

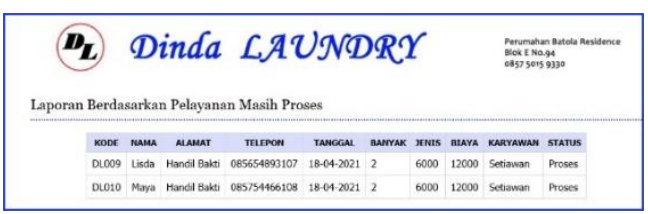

Gambar 28. Laporan Berdasarkan Pelayanan Masih Proses

4. Laporan Berdasarkan Pelayanan Sudah Selesai

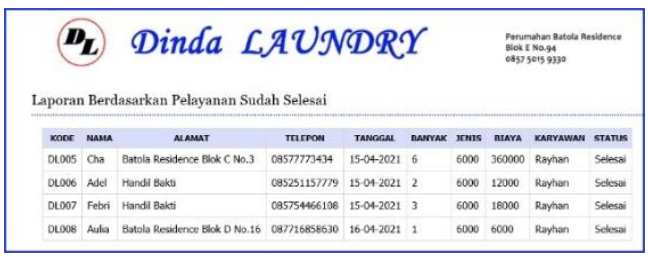

Gambar 29. Laporan Berdasarkan Pelayanan Sudah Selesai

5. Laporan Berdasarkan Pelayanan Sudah Diambil

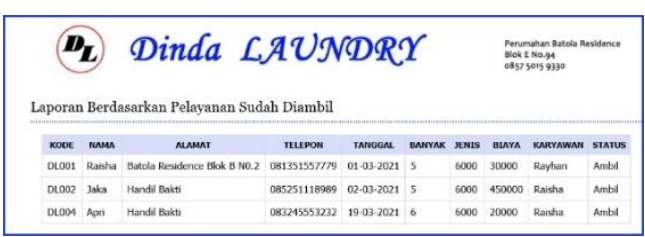

Gambar 30. Laporan Berdasarkan Pelayanan Sudah Diambil

6. Laporan Berdasarkan Pelayanan Batal

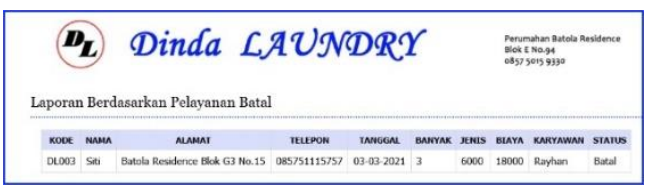

Gambar 31. Laporan Berdasarkan Pelayanan Batal

7. Laporan Berdasarkan Pelayanan Keseluruhan

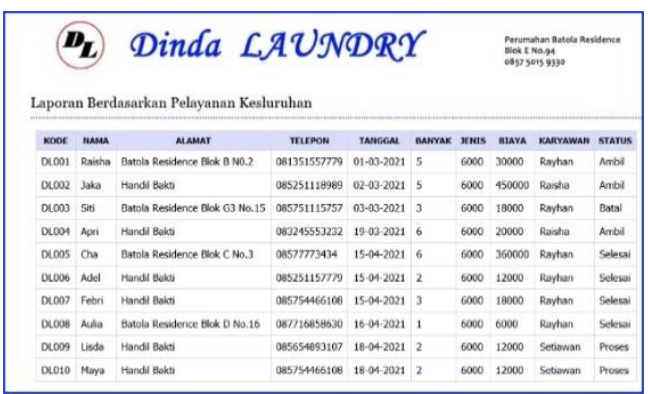

Gambar 32. Laporan Berdasarkan

Pelayanan Keseluruhan

\section{KESIMPULAN}

Penelitian dilakukan pada Dinda Laundry yang beralamat di perumahan Batola Residence, Handil Bakti, Barito Kuala, Kalimantan Selatan. Dinda Laundry melayani jasa pelayanan pencucian pakaian dengan berbagai jenis pelayanan. Metode waterfall menggambarkan pendekatan yang sistematis pada pengembangan perangkat lunak, dimulai dengan spesifikasi kebutuhan pengguna lalu berlanjut melalui tahapan-tahapan perencanaan (planning), permodelan (modeling), konstruksi (construction), serta penyerahan sistem ke pengguna (deployment), yang diakhiri dengan dukungan pada perangkat lunak lengkap yang dihasilkan.

Tujuan penelitian ini adalah agar memberikan kemudahan baik administrator, karyawan, pemilik melakukan proses serah terima pakaian kepada pelanggan, maupun proses pencarian data pelanggan secara cepat dan mudah. Aplikasi pelayanan pada Dinda Laundry dikelola oleh administrator, kemudian dilanjutakan oleh karyawan untuk mengelola data pelayanan dan terakhir pemilik toko untuk melihat data laporan. Aplikasi pelayanan pada Dinda Laundry ini dibuat menggunakan bahasa pemrograman PHP dan MySQL. Penggunaan aplikasi memudahkan untuk mendata semua data pelayanan dan menyimpan nota pelayanan apabila sewaktu-waktu diperlukan.

\section{DAFTAR PUSTAKA}

[1] Fatta, A., \& Hanif. (2007). Analisis \& Perancangan Sistem Informasi Untuk Keunggulan Bersaing perusahaan Organisasi Modern. Yogyakarta: ANDI.

[2] Peranginangin, K. (2006). Aplikasi WEB dengan PHP dan MySQL. Yogyakarta: ANDI.

[3] Sunyoto, A. (2007). Pemrograman Database dengan Visual Basic dan Microsoft SQL. Yogyakarta: ANDI.

[4] Fikri, Ihsanul., Rahman, Fauzi Y., Asegaff, ARMH., (2020). Perancangan Aplikasi Data Servis Komputer Berbasis Web Di Mellon Komputer Banjarmasin. Vol 11, No 2 (2020): Technologia (April).

[5] Wikipedia. (2019, September 7). HTML. Retrieved Oktober 1, 2019, from 
Wikipedia:

https://id.wikipedia.org/wiki/HTML

[6] Wikipedia. (2019, Oktober 1). MySQL.

Retrieved from Wikipedia:

https://id.wikipedia.org/wiki/MySQL

[7] Wikipedia. (2019, September 20). PHP.

Retrieved Oktober 1, 2019, from

Wikipedia:

https://id.wikipedia.org/wiki/PHP 